\title{
Ensino de projeto dos sistemas prediais hidráulicos e sanitários: abordagem baseada em problemas
}

\author{
Teaching plumbing systems design: problem based \\ learning
}

\section{Letícia Santos Machado de Araújo Marina Sangoi de Oliveira Ilha}

\section{Resumo}

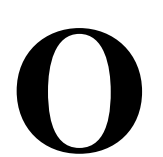

escopo e a complexidade do projeto dos sistemas prediais hidráulicos e sanitários vêm aumentando ao longo dos anos, sendo necessário que os alunos de graduação desenvolvam habilidade de análise. Além disso, a dificuldade de concentração por longos períodos, característica dos jovens na atualidade, fazem com que as aulas expositivas sejam cada vez menos eficazes na construção do conhecimento. Inserido nesse contexto, este artigo objetiva avaliar o uso da abordagem baseada em problemas em duas disciplinas do curso de Engenharia Civil voltadas para o projeto desses sistemas. Foram propostas situações-problema para o desenvolvimento do conteúdo. A avaliação da aplicação foi efetuada por meio de entrevista coletiva e de questionários estruturados aplicados aos alunos e aos docentes, além das notas obtidas pelos alunos nas atividades propostas. Os resultados obtidos indicam certa resistência dos alunos em adotar uma atitude proativa no seu aprendizado, sem o devido estudo prévio e a dependência do docente durante a realização das atividades. Verificou-se que a carga horária elevada dos alunos contribuiu para esse resultado, sendo importante repensar o curso como um todo, preferencialmente de forma interdisciplinar. Há que se pensar em estratégias que motivem e que auxiliem os alunos no estudo e na preparação prévios.

Palavras-chave: Ensino. Aprendizagem. Sistemas prediais hidráulicos e sanitários. Abordagem baseada em problemas. ABP.

${ }^{1}$ Letícia Santos Machado de Araújo

${ }^{1}$ Instituto Federal de Educação, Ciência e Tecnologia de São Paulo São Paulo - SP - Brasil

${ }^{2}$ Marina Sangoi de Oliveira Ilha ${ }^{2}$ Universidade Estadual de Campinas Campinas - SP - Brasil

Recebido em 19/04/18 Aceito em 01/07/18

\begin{abstract}
The scope and complexity of plumbing systems design have been increasing over the years, so it is necessary for undergraduate students to develop analytical skills. Besides, certain characteristics of today's youngsters, especially their difficulty to focus for longer periods of time, make lectures less effective when it comes to building knowledge. This paper evaluates the use of Problem-Based Learning $(P B L)$ in two disciplines of the undergraduate course in Civil Engineering related to the building systems. Problem situations were proposed for program content development in the semesters under study. The PBL application was evaluated through collective interviews and questionnaires applied to students and professors, as were the marks obtained by the students in the proposed activities. The results indicate some resistance on the part of the students to taken on a proactive attitude in their learning without prior study and dependency on the professor during the activities. The students' high workload contributed to this result. Hence, it is important to rethink the undergraduate course as a whole, preferentially in an interdisciplinary way, rather than just applying teachinglearning strategies in isolated subjects. In addition, it is necessary to develop strategies that motivate and help students in prior study and preparation.
\end{abstract}

Keywords: Teaching. Learning. Plumbing systems. Problem-based learning. PBL. 


\section{Introdução}

O ensino de Engenharia Civil no Brasil possui em geral um cunho profissionalizante, com foco na transmissão de conhecimentos (SILVA et al., 2016). Contudo, considerando que os engenheiros civis trabalharão em uma sociedade em constante evolução, os cursos de graduação devem auxiliar seus alunos a adquirirem as habilidades de análise e de discussão, necessárias para sua vida profissional, em vez de dotá-los apenas de conhecimentos.

Dagnino e Novaes (2007) relatam que é clara a dissociação da teoria e da prática por parte dos alunos dos cursos de Engenharia, o que evidencia a necessidade de uma mudança no processo de sua formação.

A evolução do ensino profissionalizante, baseado na transmissão de conhecimentos, para uma perspectiva mais integrada, com o foco na resolução dos problemas, requer novas abordagens (HALBE, ADAMOWSKI, PAHL-WOSTL, 2015). Deve-se investir em estratégias de ensinoaprendizagem, nas quais a prática seja o ponto de partida para questionamentos, unindo as reflexões teórica e social. O aluno deve vivenciar o problema, reconhecendo o que tem de geral e explicativo e o que tem de único e singular (PEREIRA, 2002).

A formação do engenheiro civil deve contemplar abordagens didático-pedagógicas que favoreçam simultaneamente a atenção, a motivação e o aprendizado dos alunos. Também é necessário treinar os alunos para a tomada de decisão (MARQUES FILHO, 2017). O referido autor alerta, porém, que não deve haver diminuição da bagagem teórica, pois é por meio dessa que os engenheiros desenvolvem a segurança para a tomada de decisões e a capacidade de inovação.

Dentre as atividades desenvolvidas pelos engenheiros civis, destaca-se a elaboração do projeto dos sistemas prediais hidráulicos e sanitários (SPHS), cujo escopo e complexidade têm aumentado ao longo dos últimos anos. Os projetistas devem ter domínio dos subsistemas, que compõem os SPHS e da interação entre eles, considerando os conceitos de qualidade, de desempenho e de sustentabilidade. Também devem ser capazes de acompanhar os avanços tecnológicos ao longo da sua vida profissional.

Por causa do aumento da complexidade e do escopo dos projetos de edificações, novas especialidades foram incorporadas. Além disso, usualmente cada sistema do edifício é projetado por profissionais diferentes, especializados naquele tema. Torna-se necessária a compatibilização dos projetos desenvolvidos, com a análise e correção das interferências físicas entre as diferentes soluções adotadas. O sucesso dessa atividade depende do compartilhamento das informações por parte de todos os projetistas (RUSCHEL et al., 2013).

Para dar conta desses desafios, os alunos necessitam, além do conhecimento teórico, de uma formação que os auxiliem na aquisição das habilidades de análise e de discussão. A abordagem baseada em problemas (ABP) que, segundo Steinemann (2003) e Ribeiro e Mizukami (2005) se caracteriza pelo uso de situações reais para estimular o desenvolvimento do pensamento crítico e das habilidades para solucionar problemas, se constitui em uma importante estratégia para se atingir esses objetivos na formação dos engenheiros civis.

Este artigo tem como objetivo avaliar a utilização da ABP no ensino do projeto dos SPHS e as questões norteadoras do seu desenvolvimento foram:

(a) Há entraves para a utilização dessa estratégia de ensino-aprendizagem? Caso afirmativo, quais são eles e como contorná-los?

(b) Atividades no formato de soluções problema facilitam a aprendizagem? O desempenho dos alunos é satisfatório? e

(c) Há uso/desenvolvimento de habilidades necessárias para o futuro exercício da profissão dentro dessa estratégia de ensino-aprendizagem?

\section{Referencial teórico}

As primeiras pesquisas sobre a ABP no ensino de Engenharia datam da década de 70. Com foco principal na descrição e na conceituação, essas pesquisas auxiliaram no processo de mudança dos paradigmas do ensino-aprendizagem. Nas duas décadas seguintes, as aplicações da ABP passaram de conceituais e descritivas para empíricas, com avaliações dos resultados quantitativas e/ou qualitativas (DU; GRAAFF; KOLMOS, 2009). Embora existam pesquisas sobre a aplicação da ABP na engenharia desde a mesma época, ainda é pequena a parcela de estudos sobre esse tema na Engenharia Civil (REIS; BARBALHO; ZANETTEA, 2017).

Em um levantamento de artigos de periódicos publicados em inglês, indexados em 3 bases de dados internacionais (Web of Science, Scopus e Engineering Village), realizado entre dezembro de 2017 e janeiro de 2018, foram encontrados estudos sobre a ABP na Engenharia Civil em três níveis de aplicação: filosofia e estrutura curricular (HADGRAFT, 1993; VANDEBONA; ATTARD, 
2002); em duas ou mais disciplinas (FERNANDEZ et al., 2010; FERNANDES, FLORES, LIMA, 2012) e em uma disciplina isolada, limitando-se aos seus conteúdos (RIBEIRO; MIZUKAMI, 2005; FREIRE et al., 2016).

A aplicação da ABP apresenta vários resultados positivos, destacando-se:

(a) o desenvolvimento de competências e de habilidades não técnicas, tais como comunicação, trabalho em equipe e resolução de problemas (RIBEIRO, MIZUKAMI, 2005; BARRY et al., 2008; VIDIC, 2016); e

(b) o aumento da motivação e maior facilidade para aprendizado dos alunos (SILVA; KURI; CASALE, 2012; EL-MAADDAWY; DENEEN, 2017; SHEKHAR; BORREGO, 2017).

Há relatos na literatura de um melhor desempenho acadêmico nos alunos que cursam disciplinas com a aplicação de ABP quando comparados a alunos que cursaram disciplinas com outras estratégias de ensino-aprendizado (BOXALL; TAIT, 2008; DE JUSTO; DELGADO, 2005).

Contudo, a ABP exige maior disponibilidade de tempo para preparação e correção das atividades por parte dos docentes (DE JUSTO; DELGADO, 2005; SOLÍS; ROMERO; GALVÍN, 2012; SHEKHAR; BORREGO, 2017), além de maior dedicação de tempo por parte dos alunos (DE JUSTO; DELGADO, 2005; SHEKHAR; BORREGO, 2017).

Considerando-se os estudos levantados nas bases internacionais que relatam o uso da ABP em disciplinas isoladas, foram encontradas aplicações nas áreas de estruturas (BARROSO; MORGAN, 2012; DE JUSTO; DELGADO, 2015); de transportes (AHERN, 2010; SILVA; KURI; CASALE, 2012; SILVA; FONTENELE; SILVA, 2015); de construção civil (RIBEIRO; MIZUKAMI, 2005; FREIRE et al., 2016); de hidráulica (BOXALL; TAIT, 2008; DE LEÓN, 2016); de segurança do trabalho (VIDIC, 2016) e de tratamento de esgoto e água (BARRY et al., 2008). Apenas dois estudos abordam os sistemas prediais: Apul e Philpott (2011) abordam o projeto do sistema de irrigação de um campus universitário; Antón et al. (2011) aplicam a ABP no ensino-aprendizagem do projeto de instalações elétricas residenciais.

Um levantamento dos artigos publicados em periódicos de associações científicas brasileiras voltadas para a Engenharia Civil, realizado entre dezembro de 2017 e janeiro de 2018, revelou a existência de apenas três artigos, os quais abordam a aplicação da ABP em disciplinas isoladas, inseridas em uma estrutura curricular convencional
(KURI; SILVA, 2010; CARDOSO; LIMA, 2012; PICHI JUNIOR; GATTI; SILVA, 2015).

Não foram encontrados, tanto na literatura estrangeira como na nacional, estudos voltados para aplicação da ABP no ensino dos SPHS.

Segundo um levantamento realizado por Ilha et al. (2006), tendo como fonte os Encontros Nacionais de Tecnologia do Ambiente Construído (ENTAC), as pesquisas em SPHS no Brasil têm focado principalmente em conservação de água. Consultando-se os anais desses eventos, nas edições realizadas desde 2006, verifica-se que esse tema continua a ser o mais pesquisado no país (ENCONTRO..., 2006, 2008, 2010, 2012, 2014, 2016).

\section{Método}

Este trabalho consiste em uma pesquisa-ação desenvolvida em duas disciplinas diferentes do curso de graduação em Engenharia Civil que contemplam o projeto dos sistemas prediais hidráulicos e sanitários. As duas disciplinas são oferecidas em semestres subsequentes e a primeira é pré-requisito para a segunda, entretanto, nem todos os alunos cursam as duas disciplinas no mesmo ano.

A disciplina 1 aborda o projeto dos sistemas prediais de água fria e quente, esgoto sanitário, água pluvial, gás combustível e combate a incêndios com hidrantes e mangotinhos. $\mathrm{Na}$ disciplina 2, são abordados dois tópicos:

(a) gestão da água no lote (uso racional, aproveitamento de água pluvial, reuso e infiltração; e

(b) sistemas de detecção e alarme e combate a incêndios com chuveiros automáticos.

Para a disciplina 1, inicialmente foi levantado, junto ao docente responsável, o programa e as atividades desenvolvidas no último oferecimento. A partir disso, foram propostas atividades (aqui denominadas de situações-problema), tendo em vista uma participação mais ativa dos alunos e tomando como base a literatura levantada e a experiência das autoras desse trabalho, as quais são docentes da área.

O Quadro 1 apresenta as atividades desenvolvidas na disciplina 1 em oferecimentos anteriores e no presente estudo. As aulas dessa disciplina têm a duração de 3 horas cada. Destaca-se que essa disciplina sempre contou com o desenvolvimento do projeto dos sistemas hidráulicos e sanitários (SPHS) de um edifício residencial multifamiliar, o que não foi modificado. O referido projeto contempla (1) a concepção e o dimensionamento 
dos sistemas prediais de água pluvial, esgoto sanitário, água fria e água quente de um banheiro, cozinha e lavanderia do apartamento-tipo; (2) a reserva e a distribuição de água fria e (3) a captação de água pluvial na cobertura. Essa atividade não consta no Quadro 1, pois não constituiu escopo do presente estudo.
Os alunos da disciplina 1 estavam divididos em duas turmas (A e B), com 42 e 41 alunos matriculados, respectivamente. As aulas foram ministradas no mesmo horário, por dois docentes diferentes e dois auxiliares (alunos da pósgraduação em estágio docente).

\section{Quadro 1 - Atividades desenvolvidas na disciplina 1}

\begin{tabular}{|c|c|c|}
\hline Tópico & Último oferecimento & Presente estudo \\
\hline $\begin{array}{l}\text { Introdução aos sistemas prediais } \\
\text { hidráulicos, sanitários e de gás } \\
\text { combustível. }\end{array}$ & $\begin{array}{l}\text { Exposição pelo professor - } \\
1 \text { aula }\end{array}$ & $\begin{array}{l}\text { Exposição pelo professor - } 1 \text { aula } \\
1^{\text {a }} \text { situações-problema (SP1) - } 1 \text { aula }\end{array}$ \\
\hline $\begin{array}{l}\text { Condicionantes do projeto do } \\
\text { Sistema predial de esgoto sanitário } \\
\text { (SPES) - concepção e } \\
\text { dimensionamento. }\end{array}$ & $\begin{array}{l}\text { Exposição pelo } \\
\text { professor/desenvolvimento } \\
\text { de exercício de } \\
\text { dimensionamento - } 1 \text { aula }\end{array}$ & $\begin{array}{l}2^{\mathrm{a}} \text { situações-problema (SP2) - } 1 \text { aula } \\
\text { Exposição pelo professor - } 1 \text { aula }\end{array}$ \\
\hline $\begin{array}{l}\text { Condicionantes do projeto do } \\
\text { Sistema predial de água pluvial } \\
\text { (SPAP) - concepção e } \\
\text { dimensionamento. }\end{array}$ & $\begin{array}{l}\text { Aula expositiva / } \\
\text { desenvolvimento de } \\
\text { exercício de } \\
\text { dimensionamento - } 1 \text { aula }\end{array}$ & idem ao último oferecimento - 1 aula \\
\hline $\begin{array}{l}\text { Condicionantes do projeto dos } \\
\text { Sistemas prediais de água fria } \\
\text { (SPAF) e quente (SPAQ) - } \\
\text { concepção e dimensionamento. }\end{array}$ & $\begin{array}{l}\text { Aula expositiva / } \\
\text { desenvolvimento de } \\
\text { exercício de } \\
\text { dimensionamento - } 2 \text { aulas }\end{array}$ & $\begin{array}{l}3^{\mathrm{a}} \text { situações-problema (SP3) - } 1 \text { aula } \\
\text { 4a situações-problema (SP4) - } 1 \text { aula } \\
\text { Exposição pelo professor - } 1 \text { aula }\end{array}$ \\
\hline $\begin{array}{l}\text { Condicionantes do projeto dos } \\
\text { sistemas prediais de gás combustível } \\
\text { e de combate a incêndio com } \\
\text { hidrantes, mangotinhos e extintores - } \\
\text { concepção e dimensionamento. }\end{array}$ & $\begin{array}{l}\text { Aula expositiva/ } \\
\text { desenvolvimento de } \\
\text { exercício de } \\
\text { dimensionamento - } 1 \text { aula }\end{array}$ & $\begin{array}{l}\text { Aula expositiva - } 1 \text { aula } \\
5^{\text {a }} \text { situações-problema (SP5): } \\
\text { Dimensionamento de sistema predial } \\
\text { de combate a incêndio por hidrante / } \\
\text { Avaliação coletiva e aplicação dos } \\
\text { questionários individuais - } 1 \text { aula }\end{array}$ \\
\hline $\begin{array}{l}\text { Introdução aos sistemas prediais } \\
\text { hidráulicos, sanitários e de gás } \\
\text { combustível. }\end{array}$ & $\begin{array}{l}\text { Exposição pelo professor - } \\
1 \text { aula }\end{array}$ & $\begin{array}{l}\text { Exposição pelo professor - } 1 \text { aula } \\
1^{\mathrm{a}} \text { situações-problema (SP1) - } 1 \text { aula }\end{array}$ \\
\hline
\end{tabular}

Quadro 2 - Situações-problema propostas na disciplina 1

\begin{tabular}{|l|l|}
\hline $\begin{array}{l}\text { Situações- } \\
\text { Problema }\end{array}$ & \multicolumn{1}{c|}{ Atividades propostas } \\
\hline SP1: & $\begin{array}{l}\text { Análise dos espaços destinados aos SPHS e pré-dimensionamento do sistema individual de } \\
\text { água quente (aquecedor de acumulação a gás e sistema de recirculação de água). }\end{array}$ \\
\hline SP2: & $\begin{array}{l}\text { Análise do projeto do SPES dos ambientes sanitários, contemplando banheiro, cozinha e } \\
\text { área de serviço, com a adequação do traçado, caso necessário. }\end{array}$ \\
\hline SP3: & $\begin{array}{l}\text { Dimensionamento do caminho crítico do sistema predial de água fria (SPAF) de um edifício } \\
\text { residencial multifamiliar. }\end{array}$ \\
\hline SP4: & $\begin{array}{l}\text { Verificação do dimensionamento do sistema predial individual de água quente com três } \\
\text { materiais: cobre, CPVC e PPR. Análise dos custos dessas instalações e escolha do material a } \\
\text { ser utilizado. }\end{array}$ \\
\hline Nota: Legenda: \\
SPES - Sistema Predial de Esgoto Sanitário; \\
SPHS - Sistemas Prediais Hidráulicos e Sanitários; \\
CPVC - Policloreto de Vinila Clorado; e \\
PPR - Polipropileno Copolímero Random.
\end{tabular}


Todas as atividades realizadas contaram com a participação das autoras desse trabalho.

A ABP adotada nesse estudo contemplou cinco etapas, adaptadas de Maastrich University (2017): preparação pré-aula por parte dos alunos, apresentação e discussão das situações-problema, desenvolvimento da solução e apresentação dos resultados pelos alunos

O programa da disciplina foi apresentado aos alunos no primeiro dia de aula, com a descrição das atividades a serem desenvolvidas e a forma e os critérios de avaliação. O Quadro 2 apresenta as situações-problema (SP) propostas nesse estudo para a disciplina 1.

A título de ilustração, o Quadro 3 apresenta o enunciado da SP2.

Segundo a experiência prévia das autoras, os alunos de graduação de Engenharia Civil geralmente desconhecem o processo de montagem/instalação dos SPES, o que dificulta a compreensão do projeto. Com o objetivo de facilitar a análise do projeto, o escopo da SP2, foram propostos "kits" (Figura 1) para os alunos montarem, os quais são constituídos por bases em lona com o traçado do SPES, tubos previamente cortados nos comprimentos adequados e conexões.

Para o acompanhamento da disciplina 1 em oferecimentos anteriores, os alunos contavam com cinco apostilas disponibilizadas em ambiente virtual. Para o presente estudo, foi disponibilizado, também em ambiente virtual, material complementar relativo ao Sistema Predial de Esgoto Sanitário, com novas figuras e exemplos de projetos desse sistema, além de exercícios de fixação.

Na semana anterior a cada aula que contaria com o desenvolvimento das situações-problema, os alunos eram orientados quanto à preparação necessária. Foi solicitado aos alunos, no caso da:

(a) SP1: estudo das apostilas de qualidade dos SPHS e SPAQ;

(b) SP2: estudo do material complementar dos SPES e resolução dos exercícios de fixação;

(c) SP3: estudo do item de dimensionamento da apostila do SPAF; e

(d) SP4: estudo do item de dimensionamento da apostila do SPAQ.

\section{Quadro 3 - Enunciado da SP2 - disciplina 1}

Vocês foram contratados por uma incorporadora como consultores do projeto e da execução do sistema predial de esgoto sanitário (SPES) de um edifício residencial multifamiliar. O edifício em questão será construído em Campinas e contará com 15 andares tipo, térreo com áreas de lazer e garagem no subsolo. A incorporadora deseja que vocês analisem a solução do escritório projetista quanto à qualidade do projeto e ao desempenho do SPES.

O escritório projetista entregou o detalhe e as vistas (escala 1:20) dos ambientes sanitários do apartamento tipo (em ANEXO).

Para facilitar sua análise, vocês criaram um roteiro a ser seguido:

1.1) O projeto dos SPES atende à NBR 8160/1999: Sistemas prediais de esgoto sanitário - Projeto e execução? Justifiquem.

1.2) O projeto dos SPES foi pensado de modo a evitar entupimentos e também prevê dispositivos para a manutenção dos SPES? Justifiquem.

1.3) O escritório projetista não entregou a solução com tubos de queda exclusivos para receber os efluentes do primeiro e do segundo andar. Considerando que os shafts dos apartamentos tipos se mantêm no mesmo alinhamento no pavimento térreo e que os desvios só ocorrem no teto do subsolo, justifiquem a necessidade de tubos de queda exclusivos para o primeiro e segundo andar.

1.4) A partir do exposto no item 1.3., solicita-se que vocês proponham um traçado (eixo) do SPES para o primeiro e segundo andar tipo, localizando os tubos de queda no shaft.

1.5) Considerando que o pé-direito mínimo exigido pela legislação nessa tipologia de edifício é de 2,70 m de altura para ambientes de longa permanência e 2,50 metros para ambientes de curta permanência, é possível executar a montagem do SPES em 0,18 m (entre a face inferior da laje e a face superior do forro de gesso, considerando-se uma espessura mínima do forro de 0,02 m)? Justifiquem.

1.6) Caso a resposta ao item 1.5 seja negativa, qual seria a altura mínima entre a face inferior da laje e a face superior do forro de gesso? É possível diminuir esse espaço? Justifiquem.

Vocês aprovam o projeto sem correções? Vocês aprovam o projeto com correções? Justifiquem e apontem as correções necessárias. 
Figura 1 - Kit do sistema predial de esgoto sanitário: disciplina 1

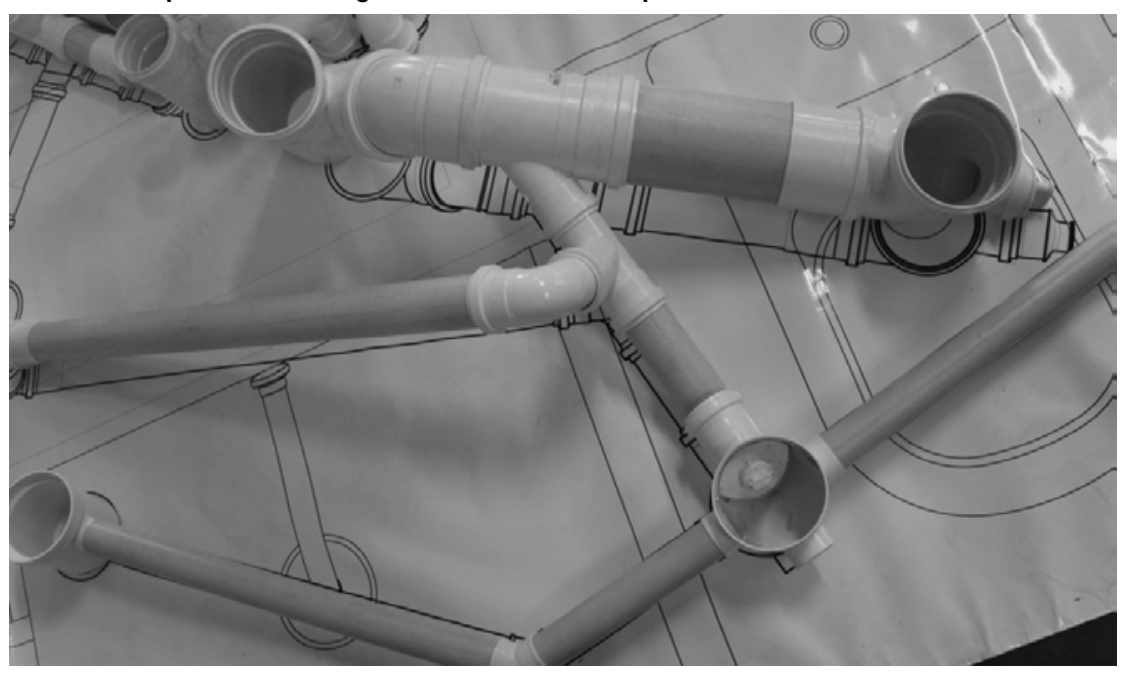

No dia da aula que seria desenvolvida com situações-problema, os grupos recebiam uma pasta com o enunciado da SP e trabalhavam em grupos com três integrantes, sendo 15 grupos na Turma A e 14 grupos na Turma B. No fim da aula, cada grupo entregava um relatório. Os relatórios foram posteriormente corrigidos pelos docentes. Foram comentados, em sala de aula, os erros mais comuns e as soluções que se destacaram

Cada uma das situações-problema foi avaliada de forma qualitativa ao longo do seu desenvolvimento e também quantitativamente, por meio da atribuição de uma nota de zero a dez.

Para a análise dos dados, foram determinados a média e o coeficiente de variação das notas obtidas pelos alunos.

Foi realizada, também, uma entrevista coletiva e aplicado um questionário individual para o levantamento da percepção dos alunos sobre a metodologia de ensino empregada na disciplina naquele semestre.

A entrevista coletiva, conduzida conjuntamente para as duas turmas pelo docente responsável pela Turma A no último dia de aula do semestre, contou também com a presença das autoras desse trabalho, além do docente e do estagiário docente da Turma B. Foram propostas questões não estruturadas e, a partir das respostas obtidas, questões complementares foram formuladas.

O questionário individual contém questões de única escolha e dissertativas. Tanto o questionário individual como o termo de livre consentimento foram aprovados pelo Comitê de Ética (CEP) da instituição onde a pesquisa foi desenvolvida. A fim de não introduzir viés nos resultados da pesquisa, os alunos foram informados sobre o desenvolvimento da pesquisa somente no momento da aplicação do questionário, ao fim do semestre.

Para cada questão de escolha única, foi atribuída uma escala de 0 (não contribuiu/pouco adequado) a 5 pontos (contribuiu muito/muito adequado), conforme De Justo e Delgado (2015), El-Adaway, Pierrakos e Truax (2015), e Shekhar e Borrego (2017). Posteriormente foram determinados as médias e o desvio padrão dos resultados. Já os resultados das questões dissertativas foram analisados segundo as recomendações de Batista e Campos (2016).

A percepção dos docentes e dos estagiários docentes foi levantada por meio de questionário, o qual foi também aprovado pelo Comitê de Ética e Pesquisa (CEP-UNICAMP). Os resultados obtidos foram analisados de forma análoga aos questionários individuais dos alunos.

O mesmo método de pesquisa foi aplicado na disciplina 2, contudo, essa disciplina já vinha sendo oferecida a partir do desenvolvimento de situaçõesproblema. A principal modificação foi a consideração de uma mesma edificação para o desenvolvimento de todas as atividades. Vale destacar que os resultados da entrevista coletiva realizada na disciplina 1 foram utilizados para promover melhorias na disciplina 2.

Na disciplina 2, a aplicação da ABP foi composta por cinco etapas, adaptadas de Prince e Felder (2006) e Ahern (2010): apresentação e discussão das situações-problema; minipalestras sobre o tema ministradas pelo docente; desenvolvimento da solução e apresentação dos resultados pelos discentes. 
O programa foi apresentado aos alunos no primeiro dia de aula, com a descrição das atividades a serem desenvolvidas e com os critérios de avaliação.

A disciplina 2 contou com apenas uma turma, com 32 alunos matriculados, e foi ministrada por um docente, auxiliado por um estagiário. De maneira similar, todas as atividades contaram com a participação das autoras deste trabalho. O Quadro 4 apresenta as atividades desenvolvidas na disciplina 2 em oferecimentos anteriores e no presente estudo. As aulas dessa disciplina têm a duração de 2 horas cada. Analogamente à disciplina 1 , as atividades que não foram objeto do presente estudo não constam no Quadro 4.

O Quadro 5 apresenta as situações-problema (SP) propostas nesse estudo para a disciplina 2.

A título de ilustração, o Quadro 6 apresenta o enunciado da SP1 desenvolvida na disciplina 2.

Cada um dos nove grupos de quatro alunos trabalhou com uma edificação escolar hipotética diferente. Os anexos contemplavam os projetos arquitetônicos com pontos de consumos de água cadastrados, o levantamento dos vazamentos visíveis e não visíveis, dos hábitos de consumo dos usuários (uso da água para o preparo de refeições, rega de jardim, entre outras) e o relatório fotográfico da edificação.

A coleta e o tratamento dos dados da pesquisa foram efetuados de maneira similar à disciplina 1 .

Os critérios de avaliação das duas disciplinas e as condicionantes para a aprovação foram mantidos conforme os oferecimentos anteriores. No caso da disciplina 1, todas as notas (relatórios das SP, projetos desenvolvidos e provas) deveriam ser iguais ou superiores a 5,0. A nota inferior a 5,0 em quaisquer atividades implicaria realização de exame do conteúdo nelas contemplado e a nota obtida no exame substituiria a(s) nota(s) inferiores a 5,0 na determinação do aproveitamento do aluno. Na disciplina 2, apenas as notas das provas deveriam ser iguais ou superiores a 5,0.

Quadro 4 - Atividades desenvolvidas na disciplina 2

\begin{tabular}{|c|c|c|}
\hline Tópico & Último oferecimento & Presente estudo \\
\hline $\begin{array}{l}\text { Conservação de água em } \\
\text { edificações - uso racional. }\end{array}$ & $\begin{array}{l}\text { Exposição pelo professor - } 1 \text { aula } \\
\text { Tutoria ao desenvolvimento de } \\
\text { exercício - } 2 \text { aulas }\end{array}$ & $\begin{array}{l}1^{\text {a }} \text { situações-problema (SP1): uso } \\
\text { racional de água em edifício } \\
\text { escolar - } 4 \text { aulas }\end{array}$ \\
\hline $\begin{array}{l}\text { Gestão da água pluvial - } \\
\text { aproveitamento como fonte } \\
\text { alternativa. }\end{array}$ & $\begin{array}{l}\text { Exposição pelo professor - } 1 \text { aula } \\
\text { Tutoria ao desenvolvimento de } \\
\text { exercício - } 2 \text { aulas }\end{array}$ & $\begin{array}{l}2^{\mathrm{a}} \text { situações-problema (SP2): } \\
\text { aproveitamento de água de chuva } \\
\text { em edifício escolar - } 2 \text { aulas }\end{array}$ \\
\hline $\begin{array}{l}\text { Gestão da água pluvial - } \\
\text { drenagem no lote. }\end{array}$ & $\begin{array}{l}\text { Exposição pelo professor - } 1 \text { aula } \\
\text { Tutoria ao desenvolvimento de } \\
\text { exercício - } 1 \text { aula }\end{array}$ & $\begin{array}{l}3^{\mathrm{a}} \text { situações-problema (SP3): } \\
\text { drenagem no lote em edifício } \\
\text { escolar - } 1 \text { aula }\end{array}$ \\
\hline $\begin{array}{l}\text { Conservação de água em } \\
\text { edificações: reuso de águas } \\
\text { cinzas. }\end{array}$ & $\begin{array}{l}\text { Exposição pelo professor - } 1 \text { aula } \\
\text { Tutoria ao desenvolvimento de } \\
\text { exercício - } 1 \text { aula }\end{array}$ & $\begin{array}{l}4^{\mathrm{a}} \text { situações-problema (SP4): reuso } \\
\text { de água cinza em edifício } \\
\text { escolar - } 2 \text { aulas }\end{array}$ \\
\hline
\end{tabular}

\section{Quadro 5 - Situações-problema propostas na disciplina 2}

\begin{tabular}{|l|l|}
\hline $\begin{array}{l}\text { Situações- } \\
\text { Problema }\end{array}$ & \multicolumn{1}{c|}{ Atividades propostas } \\
\hline SP1: & $\begin{array}{l}\text { Realizar o diagnóstico e propor um plano de ação para implantação de programa de uso } \\
\text { racional de água. }\end{array}$ \\
\hline SP2: & Análise da viabilidade técnica da implantação de sistema de reuso de águas cinzas. \\
\hline SP3: & $\begin{array}{l}\text { Análise da viabilidade técnica da implantação de sistema de aproveitamento de água de } \\
\text { chuva. }\end{array}$ \\
\hline SP4: & Análise da viabilidade técnica da implantação de sistemas de infiltração. \\
\hline
\end{tabular}




\section{Quadro 6 - Enunciado da SP1 - disciplina 2}

Vocês são parte da equipe de engenheiros da Prefeitura de Pirapora do Norte, que está implantando um Programa de Uso Racional da Água nas escolas municipais. Esse programa está estruturado em quatro etapas:

1) Auditoria do consumo de água: levantamento documental e cadastral do edifício e a observação dos procedimentos adotados pelos usuários nas atividades que consomem água.

2) Diagnóstico: organização das informações obtidas na etapa anterior. A partir dos resultados obtidos, gera-se o histórico de indicador de consumo e estima-se o desperdício.

3) Plano de intervenção: ações propostas para a melhoria do desempenho do sistema, contemplando: correção de vazamentos, substituição de sistemas e componentes convencionais por economizadores de água e campanha de conscientização de usuários.

4) Avaliação do impacto de redução do consumo: verificação dos efeitos das alterações realizadas pelo monitoramento periódico do volume de água consumido, comparando-o ao consumo da edificação antes da implementação do Programa de Uso Racional da Água.

Vocês são responsáveis pela auditoria do consumo de água, diagnóstico e confecção de plano de intervenção da ESCOLA A. A escola foi construída em 1980 e está localizada na Rua Pedro Alvares Cabral $n^{\circ}$. 150, Jardim Independência, Pirapora do Norte.

A referida escola atende 160 alunos de 2 a 6 anos, em dois turnos: matutino das 8 h às $12 \mathrm{~h}$ e vespertino das $13 \mathrm{~h}$ às $17 \mathrm{~h}$. Em cada período, são servidos para os alunos do período: uma refeição quente (sopa) e um lanche (fruta ou bolo com suco).

O Programa de Uso Racional da Água está sendo desenvolvido com parceria da Concessionária de Água de Pirapora do Norte (CAPN). A CAPN, em outubro de 2016, realizou na ESCOLA A, a detecção dos vazamentos visíveis e não visíveis.

IMPORTANTE: No ANEXO A, vocês encontram o histórico de consumo de água dos últimos quatro anos e o resultado do levantamento cadastral da escola. No ANEXO B, vocês encontram um exemplo de relatório de auditoria e diagnóstico.

\section{Resultados e Discussões}

\section{Disciplina 1}

Setenta e três alunos (88\% do total de matriculados) participaram da entrevista coletiva; responderam ao questionário individual e consentiram com o uso dos dados nas avaliações para o presente estudo.

Na entrevista coletiva, os alunos da disciplina 1 relataram que esperavam respostas mais diretas/completas dos professores e estagiários docentes durante o desenvolvimento das situaçõesproblema e que sentiam falta das aulas teóricas. Afirmaram também que o ideal seria que essa metodologia fosse implantada desde o início do curso, para que eles se acostumassem gradualmente.

Em geral, a opinião dos alunos coletada na entrevista coletiva pode ser dividida em três grupos:

(a) um afirmou que esta foi a disciplina em que eles mais haviam aprendido em sala de aula; que faltava prática na maioria das disciplinas da graduação em Engenharia Civil e que a ABP deveria ser adotada nas demais disciplinas também;

(b) outro discordou das afirmações anteriores, indicando que aulas expositivas seguidas de exercícios são as estratégias mais eficazes de aprendizagem; e

(c) o terceiro, composto pela maior parte dos alunos, afirmou que o problema era a aplicação da ABP em um currículo tradicional, com uma grande carga horária de aulas presenciais. Segundo esses alunos, a carga horária excessiva não permitia que se preparassem para os exercícios. Além disso, o alto nível de exigência das situações-problema propostas e o curto tempo para executá-las em sala de aula fazia com que se sentissem pressionados e desanimados nos dias antecedentes às aulas em que seriam desenvolvidas as situações-problema.

Conforme verificado pelos questionários individuais, 64\% dos alunos matriculados na disciplina 1 passavam mais de 36 horas por semana em sala de aula no semestre desse estudo. 
Tabela 1 - Percepção discente e docente sobre a aplicação da ABP na disciplina 1

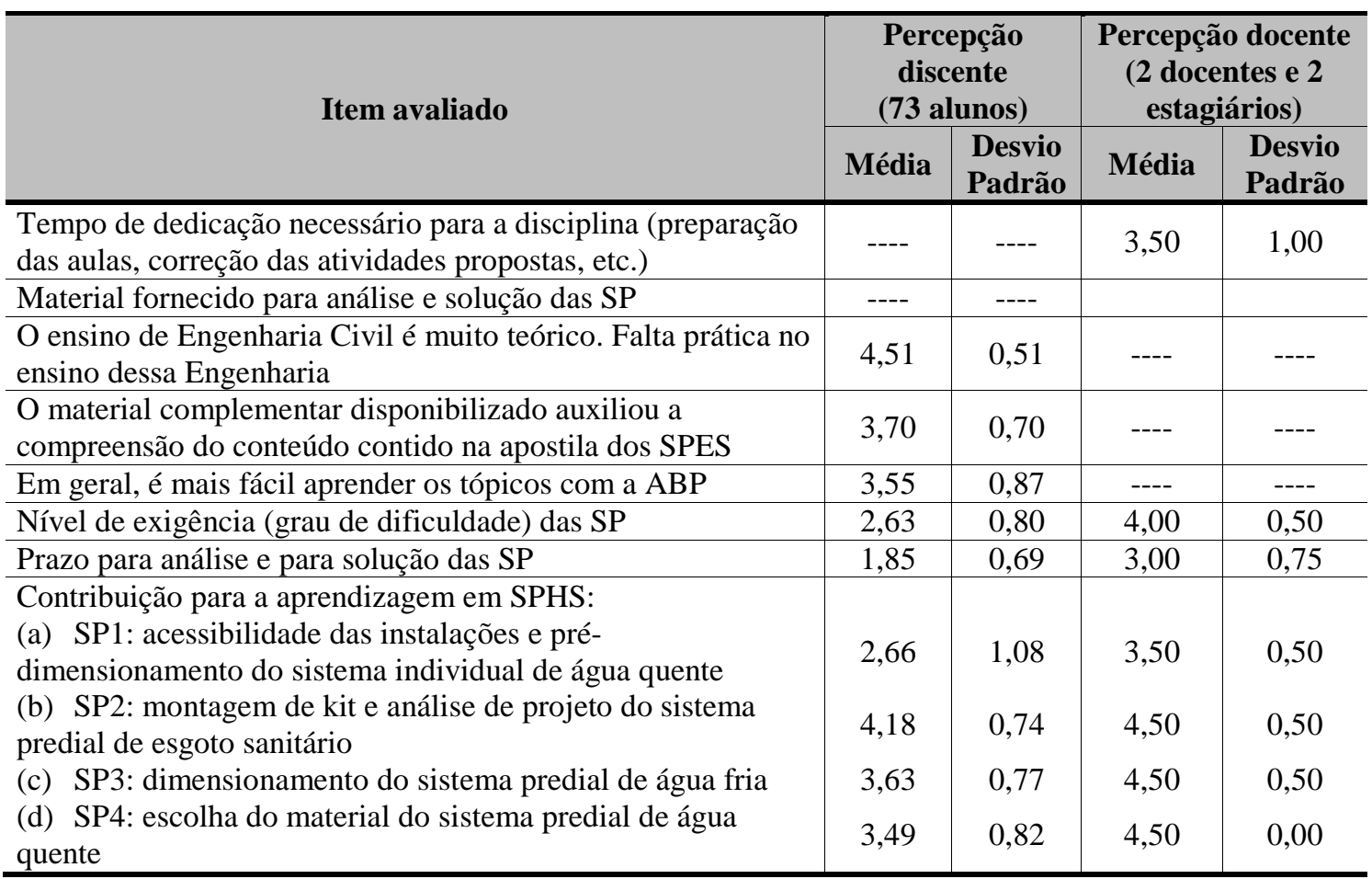

Nota: Legenda:

SPES - Sistema Predial de Esgoto Sanitário;

SPHS - Sistemas Prediais Hidráulicos e Sanitários; e

SP - situações-problema.

O ponto alto da disciplina 1, segundo os alunos, foi a montagem dos kits do SPES, o que confirma a preferência dos alunos por atividades mais práticas.

Conforme apresentado no método, as respostas dos questionários individuais foram pontuadas com escala de 0 (não contribuiu/pouco adequado) a 5 pontos (contribuiu muito/ muito adequado). A Tabela 1 apresenta a pontuação média das respostas dos questionários individuais da disciplina 1.

Setenta e cinco por cento (75\%) dos alunos que responderam ao questionário indicaram pontos positivos e/ou negativos da aplicação da ABP.

Os pontos positivos mais citados foram:

(a) proximidade com a prática profissional (20 alunos) e maior facilidade de aprendizagem (12 alunos). Afirmações de alguns alunos sobre a aplicação da ABP: “[...] vivência uma experiência de consultoria, em um prazo apertado, com muitos problemas, que faz parte da realidade no mercado de trabalho[...]"; "[...] incentiva o estudo por conta-própria [...]” e “[...] força a aprender [...]”;

(b) sobre a montagem de kit do SPES, 4 alunos comentaram: “[...] o modelo físico das tubulações foi muito interessante e ajudou a entender a execução [...]”, “[...] através da montagem das tubulações foi possível apreender melhor o conteúdo [...]”, “[...] gostei da proposta de montagem, deveria ser repetida em outras atividades [...]" e "[...] possibilitou uma experiência que não tivemos durante o curso [...]"; e

(c) a metodologia aplicada na disciplina deveria ser replicada em outras disciplinas (3 alunos).

Os pontos negativos mais citados foram:

(a) pouco tempo disponível para resolver o problema em sala de aula (22 alunos): “[...] o pouco tempo disponível [...] impedia o aprendizado, pois ficávamos mais preocupados em entregar do que aprender [...]";

(b) a ausência de aula teórica antecedendo a aplicação (11 alunos): “[...] acredito que é necessário uma explicação previa do conteúdo, o estudo por conta própria é difícil de se aplicar no nosso dia-a-dia [...]". Os alunos estudavam os conteúdos por conta própria, através do material disponibilizado no ambiente virtual, antes das aulas da situação-problema. Não houve explicação destes conteúdos por parte dos professores; e

(c) elevado nível de exigência (10 alunos): “[... a estratégia é muito interessante, contudo o nível de exigência acaba tornando o processo menos 
natural, pois pressiona os alunos e exige muito esforço previamente [...]".

Como melhoria para a disciplina 1 , oito alunos sugeriram intercalar a teoria com as situaçõesproblema. Para alguns desses alunos: “[...] ninguém aguenta prestar atenção por três horas [...]” $\mathrm{e}$ “[...] a parte expositiva ainda permanece muito cansativa [...]".

Essa observação corrobora a afirmação que consta em Purcell et al. (2012) de que o uso das tecnologias digitais teve como consequência uma geração de jovens com dificuldade de concentração por longos períodos e que se distraem facilmente.

Conforme já havia sido levantado por meio da entrevista coletiva, os alunos relataram, nos questionários individuais, que esperavam respostas mais diretas dos tutores aos questionamentos levantados durante a resolução dos problemas em sala de aula (6 alunos) e que sentiram falta da resolução das situações-problema em sala de aula (7 alunos).

Segundo os docentes e estagiários docentes, a aplicação da ABP na disciplina 1 contribuiu para a aprendizagem dos alunos. Contudo, dois pontos negativos foram citados:

(a) a falta de preparo prévio dos alunos foi citada por dois docentes: “[...] senti que eles [os alunos] não se prepararam adequadamente [...]" $e$ “[...] os alunos não se mostram totalmente confortáveis na busca ativa de conteúdo inédito [...]”; e

(b) pouco tempo para a análise e solução das situações-problema, citado por um docente: “ $O$ único ponto negativo se referiu ao tempo deixado para os alunos realizarem as atividades, que para alguns exercícios se mostrou insuficiente, levando a certa tensão por parte dos alunos, uma vez que as notas não poderiam ser inferiores a 5,0, sob pena de exame [...]".

Como sugestões de melhoria, os docentes comentaram:

(a) “Acredito que mais tempo poderia ser dedicado a mostrar os equívocos cometidos e as melhores práticas [...]”;

(b) "Considero que a estrutura está adequada, apenas os estudos de caso devem ser reduzidos, para possibilitar o seu desenvolvimento em sala de aula ou então prever a entrega posterior, com alocação de tempo hábil para o seu desenvolvimento [...]"; $\mathrm{e}$ (c) "Devido ao perfil dos alunos, considero necessárias as aulas teóricas, ainda que em carga reduzida [...]".

A Tabela 2 apresenta o desempenho dos 73 alunos nas quatro situações-problema da disciplina 1

Ao longo do desenvolvimento das atividades em sala de aula, as dúvidas levantadas pelos alunos evidenciaram que não houve, por parte deles, o estudo e a preparação prévia. Verificou-se que os alunos despediam grande parte do tempo para a compreensão do enunciado, restando pouco tempo para a análise e a solução propriamente dita.

A primeira situações-problema (SP1) foi composta de duas partes: acessibilidade das instalações e prédimensionamento do sistema individual de água quente. De modo geral, os alunos foram capazes de analisar e de propor adequações aos espaços destinados aos SPHS (shafts, carenagens, sancas e forros). Porém, as especificações dos materiais e do acesso a esses elementos ficaram aquém do desejado. Já no pré-dimensionamento do sistema individual de aquecimento de água, os alunos especificaram e localizaram o aquecedor de acumulação a gás. Contudo, apenas dois dos 29 grupos da disciplina especificaram o sistema de recirculação de água.

A SP2 também foi composta de duas partes: montagem de "kits" e análise de projeto do Sistema Predial de Esgoto Sanitário (SPES). Por meio da montagem dos "kits", os alunos foram capazes de identificar a altura mínima necessária para o forro falso. Poucos grupos (cerca de 40\%), porém, foram capazes de propor alterações no traçado e na concepção dos SPES para diminuir essa altura.

Na análise do projeto dos SPES dos ambientes sanitários, os alunos verificaram a conformidade do projeto com a NBR 8160 (ABNT, 1999), a previsão de dispositivos de inspeção e de manutenção e a verificação da necessidade de tubos de queda exclusivos para o primeiro e segundo andares. Também foi solicitada a adequação do traçado dos SPES para o primeiro e segundo andares, caso fosse necessário.

A correção dos relatórios dessa atividade evidenciou, mais uma vez, a falta de preparo prévio dos alunos. Tanto as análises realizadas quanto as adequações dos traçados dos SPES ficaram aquém do desejado.

Procurou-se, na concepção da SP3 e da SP4, diminuir a necessidade de preparo prévio por parte dos alunos, o que refletiu diretamente no desempenho deles nessas atividades. 
Tabela 2 - Desempenho discente nas quatro situações-problemas da disciplina 1

\begin{tabular}{l|cc|cc|cc|cc}
\hline \multirow{2}{*}{ Nota } & \multicolumn{2}{c|}{ SP1 } & \multicolumn{2}{c|}{ SP2 } & \multicolumn{2}{c|}{ SP3 } & \multicolumn{2}{c}{ SP4 } \\
\cline { 2 - 9 } & TA & TB & TA & TB & TA & TB & TA & TB \\
\hline Máxima & 7,64 & 7,08 & 7,92 & 9,17 & 9,72 & 9,58 & 9,50 & 10,00 \\
Média & 5,62 & 5,47 & 5,20 & 6,67 & 7,72 & 8,34 & 7,31 & 8,19 \\
Mínima & 3,88 & 3,66 & 0,83 & 3,75 & 4,44 & 4,54 & 5,00 & 5,50 \\
Coeficiente de variação & $16 \%$ & $18 \%$ & $41 \%$ & $22 \%$ & $16 \%$ & $13 \%$ & $17 \%$ & $18 \%$ \\
\hline
\end{tabular}

Nota: Legenda:

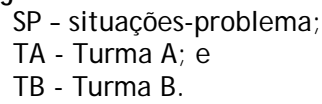

\section{Disciplina 2}

Dezenove alunos (59\% do total de matriculados) participaram da entrevista coletiva; responderam ao questionário individual e consentiram com o uso dos dados nas avaliações para o presente estudo. Destaca-se que 11 desses alunos haviam cursado a disciplina 1 no primeiro semestre e já haviam participado desse estudo.

Segundo a entrevista coletiva, a aplicação da ABP na disciplina 2 foi aprovada pela maioria dos alunos, sendo por eles destacado que:

(a) o prazo para trabalhar as situações-problema foi adequado;

(b) não houve sobrecarga de trabalho; e

(c) a utilização de um mesmo projeto (edifício escolar) dividido em quatro situações-problema auxiliou na conexão dos conteúdos.

Conforme verificado pelos questionários individuais, a maioria dos alunos (69\%) da disciplina 2 passava menos de 36 horas por semana em sala de aula no semestre desse estudo. Isso também colaborou para o resultado obtido na aplicação da ABP nessa disciplina.

As respostas dos questionários individuais foram pontuadas com escala de 0 (não contribuiu/pouco adequado) a 5 pontos (contribuiu muito/ muito adequado), conforme já descrito no Método. A Tabela 3 apresenta a pontuação média das respostas ao questionário individual da disciplina 2.

Apenas 7 alunos responderam as questões dissertativas. Como ponto a ser melhorado, 2 alunos sugeriram que fossem realizadas posteriormente a discussão e a resolução das situações-problema em sala de aula e 1 aluno ressaltou que essa metodologia não é adequada para quem cursa muitos créditos simultaneamente.

Por sua vez, 4 alunos citaram pontos positivos sobre a aplicação da ABP, destacando-se os seguintes comentários: “[...] matéria mais didática, intuitiva. Os prazos foram razoáveis e os exercícios bem construídos, facilitando o aprendizado [...]”; “[...] faz com que busquemos os conceitos na teoria para entende-los de fato e aplicar na prática [...]”; “[...] os exercícios te forçam a conhecer o conteúdo [...]"; "[...] as aulas expositivas foram mais leves [...]".

Segundo o docente da disciplina, “[...] os exercícios já estavam sendo aplicados na disciplina, apenas sem a avaliação, como foi neste semestre. Além disso, acho que o fato de contemplarem uma mesma edificação ao longo de todo semestre garantiu uma visão mais sistémica dos conteúdos pelos alunos $[\ldots]$ ".

A Tabela 4 apresenta o desempenho dos 19 alunos da disciplina 2.

Na SP1, os alunos foram capazes de realizar o diagnóstico da edificação: calcularam os indicadores de consumo e os índices de vazamentos; estimaram o volume de perdas e analisaram a percepção dos usuários. Os planos de ação, porém, ficaram aquém do desejado.

De maneira geral, os alunos propuseram apenas ações corretivas para os problemas detectados.

Na SP2 e na SP3, foram realizadas atividades similares; somente com foco diferenciado, uma delas voltada para o reuso de água cinza e a outra para o aproveitamento de água pluvial. A partir de dois cenários, os alunos estimaram a demanda e a oferta da água não potável; analisaram a viabilidade técnica e especificaram sistemas compactos para o tratamento.

Na SP2, os alunos apresentaram dificuldade em contextualizar e em analisar a viabilidade econômica das situações em estudo. Já na SP3, de maneira geral, o desempenho dos alunos foi satisfatório. Apenas dois dos nove grupos não finalizaram a atividade proposta.

Por fim, na SP4, os alunos dimensionaram três opções de sistemas de infiltração (pavimento permeável, trincheira de infiltração e poço de infiltração) e indicaram qual deles seria implantado na edificação estudada. 
Tabela 3 - Percepção discente e docente sobre a aplicação da ABP na disciplina 2

\begin{tabular}{l|c|c|c}
\hline \multicolumn{1}{c|}{ Item avaliado } & \multicolumn{2}{c}{$\begin{array}{c}\text { Percepção discente } \\
\text { (19 alunos) }\end{array}$} & $\begin{array}{c}\text { Percepção } \\
\text { docente }\end{array}$ \\
\cline { 2 - 4 } & Média & $\begin{array}{c}\text { Desvio } \\
\text { Padrão }\end{array}$ & Pontuação \\
\hline $\begin{array}{l}\text { Tempo de dedicação necessário para a disciplina (preparação das } \\
\text { aulas, correção das atividades propostas, etc.) }\end{array}$ & ------ & ------ & 4,00 \\
\hline Material fornecido para análise e solução das SP & ------ & ------ & 4,00 \\
\hline $\begin{array}{l}\text { O ensino de Engenharia Civil é muito teórico. Falta prática no } \\
\text { ensino dessa Engenharia }\end{array}$ & 4,68 & 0,47 & - ------ \\
\hline $\begin{array}{l}\text { O material complementar disponibilizado auxiliou a compreensão } \\
\text { do conteúdo contido na apostila dos SPES }\end{array}$ & 4,58 & 0,53 & ----- \\
\hline Em geral, é mais fácil aprender os tópicos com a ABP & 4,11 & 0,66 & ------ \\
\hline Nível de exigência (grau de dificuldade) das SP & 4,21 & 0,66 & 5,00 \\
\hline Prazo para análise e para solução das SP & 4,68 & 0,47 & 4,00 \\
\hline $\begin{array}{l}\text { Contribuição para a aprendizagem em SPHS: } \\
\text { (a) SP1: uso racional de água } \\
\text { (b) SP2: reuso de águas cinzas }\end{array}$ & 4,53 & 0,66 & 4,00 \\
(c) SP3: aproveitamento de água de chuva & 4,26 & 0,66 & 4,00 \\
(d) SP4: sistemas de infiltração no lote & 4,16 & 0,66 & 4,00 \\
\hline
\end{tabular}

Nota: Legenda:

SPES - Sistema Predial de Esgoto Sanitário;

SPHS - Sistemas Prediais Hidráulicos e Sanitários; e

SP - situações-problema.

Tabela 4 - Desempenho discente na disciplina 2: situações-problema e avaliação individual

Nota: Legenda: SP - situações-problema.

\begin{tabular}{l|c|c|c|c}
\hline \multicolumn{1}{c|}{ Nota } & SP1 & SP2 & SP3 & SP4 \\
\hline Máximo & 9,27 & 9,30 & 9,90 & 10,00 \\
Média & 8,04 & 8,10 & 8,68 & 8,34 \\
Mínima & 7,23 & 6,80 & 3,90 & 5,90 \\
Coeficiente de variação & $8 \%$ & $10 \%$ & $14 \%$ & $13 \%$ \\
\hline
\end{tabular}

Também nesta atividade o desempenho dos alunos foi satisfatório. Apenas um dos nove grupos da disciplina 2 não finalizou a atividade.

Não houve diferença entre a média das notas dos alunos da disciplina 2 que haviam cursado a disciplina 1 no semestre anterior e das notas dos que haviam cursado em outros semestres, o que pode indicar que apenas um semestre de contato com a $\mathrm{ABP}$ não influenciou no desempenho dos alunos

\section{Conclusão}

Segundo os alunos, as atividades no formato de soluções-problema facilitam a aprendizagem do projeto dos Sistemas Prediais Hidráulicos e Sanitários. Contudo, merecem destaque dois entraves encontrados na aplicação da ABP em uma das disciplinas analisadas nesse trabalho, o que motivou modificações quando da aplicação da ABP desenvolvida na disciplina 2: o tempo alocado para resolver as situações-problema e a necessidade de estudo prévio por parte dos alunos.
A carga horária elevada da maioria dos alunos no semestre em estudo contribuiu para que eles não se preparassem para as aulas na disciplina 1 investigada. Considera-se, então, que a aplicação da ABP de forma interdisciplinar, conforme apresentado em Rahmat e Aziz (2012), LópezQuerol et al. (2015) e Odeh, McKenna e AbuMulaweh (2017), poderia contribuir para diminuir esse problema.

Percebeu-se uma dificuldade no trabalho em grupo, corroborando com Soetanto et al. (2014), Fernandez et al. (2010), Fernandes, Flores e Lima (2012) e Lončar-Vicković et al. (2012). Essa habilidade, necessária para o futuro exercício da profissão, deve ser desenvolvida ao longo do currículo do curso. A aplicação da ABP de forma interdisciplinar também se apresenta mais adequada.

O desempenho dos alunos nas situações-problema (SP) da disciplina 2 foi mais satisfatório do que nas SP da disciplina 1. Acredita-se que os principais fatores que contribuíram para um melhor resultado 
na disciplina 2 foram: menor número de créditos cursados no semestre; ementa com menor conteúdo programático em comparação com a disciplina 1 e substituição do preparo prévio dos alunos por minipalestras ministradas pelo docente sobre o conteúdo abordado nas SP.

O estudo desenvolvido indicou que a implementação da $\mathrm{ABP}$ não deveria ser restrita a disciplinas isoladas e que é importante repensar essa estratégia de ensino-aprendizagem para o currículo do curso de Engenharia Civil como um todo. Além disso, considera-se que estratégias que motivem e que auxiliem os alunos no estudo e na preparação prévia devem ser implementadas.

\section{Referências}

AHERN, A. A. A Case Study: problem-based learning for civil engineering students in transportation courses. European Journal of Engineering Education, v. 35, n. 1, p. 109-116, Mar. 2010.

ANTÓN, A. M. et al. Project-Based Learning Used For Teaching Electrical Installations and Lighting Installations in Architecture. Journal of Industrial Engineering and Management, v. 4, n. 1, p. 123-145, 2011.

APUL, D. S.; PHILPOTT, S. M. Use of Outdoor Living Spaces and Fink's Taxonomy of Significant Learning in Sustainability Engineering Education. Journal of Professional Issues in Engineering Education and Practice, v. 137, n. 2, p. 69-77, 2011.

\section{ASSOCIAÇÃO BRASILEIRA DE NORMAS} TÉCNICAS. NBR 8160: sistemas prediais de esgoto sanitário: projeto e execução. Rio de Janeiro, 1999.

BAPTISTA, M. N.; CAMPOS, D. C. de (Orgs.). Metodologia de Pesquisa em Ciências: análises quantitativa e qualitativa. Rio de Janeiro: LTC, 2016.

BARROSO, L. R.; MORGAN, J. R. J. Developing a Dynamics and Vibrations Course For Civil Engineering Students Based on FundamentalPrinciples. Advances in Engineering Education, v. 3, n. 1, p. 1-35, 2012.

BARRY, B. E. et al. Developing Professional Competencies Through Challenge to Project Experiences. International Journal of Engineering Education, v. 24, n. 6, p. 1148-1162, 2008.
BOXALL, J.; TAIT, S. Inquiry-Based Learning in Civil Engineering Laboratory Classes.

Proceedings of the Institution of Civil

Engineers: Civil Engineering, v. 161, n. 3, p. 138-143, 2008.

CARDOSO, I. M.; LIMA, R. S. Metodologias Ativas de Aprendizagem: o uso do aprendizado baseado em problemas no ensino de logística e transportes. Transportes, v. 20, n. 3, p. 79-88, 2012.

DAGNINO, R.; NOVAES, H. T. Questionando a Formação do Engenheiro: qual poderia ser seu papel se a formação fosse outra? In: PEREIRA, E. M. A. (Org.). Universidade e Educação Geral: para além da especialização. Campinas: Alínea, 2007.

DE JUSTO, E.; DELGADO, A. Change to Competence-Based Education in Structural Engineering. Journal of Professional Issues in Engineering Education and Practice, v. 141, n. 3, 2015.

DE LEÓN, A.T. Research in and Outside the Classroom: training engineers without borders. World Transactions on Engineering and Technology Education, v. 14, n. 1, p. 113-117, 2016.

DU, X.; GRAAFF, E. de; KOLMOS, A. (Eds.). Research on PBL Practice in Engineering Education. Rotterdam: Sense Publishers, 2009.

EL-ADAWAY, I. H; PIERRAKOS, O.; TRUAX, D. D. Sustainable Construction Education Using Problem-Based Learning and Service Learning Pedagogies. Journal of Professional Issues in Engineering Education and Practice, v. 141, n. 1, 2015.

EL-MAADDAWY, T.; DENEEN, C. Outcomesbased assessment and learning: Trialling change in a postgraduate civil engineering course. Journal of University Teaching and Learning Practice, v.14, nº1, art. 10, 2017.

\section{ENCONTRO NACIONAL DE TECNOLOGIA} DO AMBIENTE CONSTRUÍDO, 11., Florianópolis, 2006. Proceedings... Florianópolis, 2006. Disponível em: <http://www.infohab.org.br/ entac/>. Acesso em: 15 jun. 2018.

ENCONTRO NACIONAL DE TECNOLOGIA DO AMBIENTE CONSTRUÍDO, 12., Fortaleza, 2008. Proceedings... Fortaleza, 2008. Disponível em: <http://www.infohab.org.br/ entac/>. Acesso em: 15 jun. 2018. 
ENCONTRO NACIONAL DE TECNOLOGIA DO AMBIENTE CONSTRUÍDO, 13., Canela, 2010. Proceedings... Canela, 2010. Disponível em: <http://www.infohab.org.br/ entac/>. Acesso em: 15 jun. 2018.

ENCONTRO NACIONAL DE TECNOLOGIA DO AMBIENTE CONSTRUÍDO, 14., Juiz de Fora, 2012. Proceedings... Juiz de Fora, 2012. Disponível em:

$<$ http://www.infohab.org.br/entac/>. Acesso em: 15 jun. 2018.

ENCONTRO NACIONAL DE TECNOLOGIA DO AMBIENTE CONSTRUÍDO, 15., Maceió, 2014. Proceedings... Maceió, 2014. Disponível em: <http://www.infohab.org.br/entac/>. Acesso em: 15 jun. 2018.

ENCONTRO NACIONAL DE TECNOLOGIA DO AMBIENTE CONSTRUÍDO, 16., São Paulo, 2016. Proceedings... São Paulo, 2016. Disponível em: <http://www.infohab.org.br/ entac/>. Acesso em: 15 jun. 2018.

FERNANDES, S.; FLORES, M. A.; LIMA, R. M. Students' Views of Assessment in Project-Led Engineering Education: findings from a case study in Portugal, Assessment \& Evaluation in Higher Education, v. 37, n. 2, p. 163-178, 2012.

FERNANDEZ, J. et al. Application of PBL Methodology to the Teaching of Engineering Project Management. Journal of Professional Issues in Engineering Education and Practice, v. 136. N. 2, p.58-63, 2010.

FREIRE, A. S. et al. The Competencies Acquisition With Simulation Application in the Course Construction Planning and Controlling. International Journal of Simulation and Process Modelling, v. 11, n. 6, p. 443-452, 2016.

HADGRAFT, R.G. Problem-Based Approach to a Civil Engineering. Education. European Journal of Engineering Education, v. 18, n. 3, p. 301-311, 1993.

HALBE, J. A.; ADAMOWSKI, J.; PAHL-

WOSTL, C. The Role of Paradigms in Engineering Practice and Education For Sustainable Development. Journal of Cleaner Production, v. 106, p. 272-282, Mar. 2015.

ILHA, M. S. O. et al. Caracterização da Produção Científica na Área dos Sistemas Prediais Hidráulicos, Sanitários e de Gás Combustível. In: ENCONTRO NACIONAL DE TECNOLOGIA DO AMBIENTE CONSTRUÍDO, 11., Florianópolis, 2006. Anais... Florianopólis: ANTAC, 2006.
KURI, N. P.; SILVA, A. N. R. da. Uma Estratégia de Ensino em Transportes Apoiada nos Perfis de Personalidade dos Estudantes. Transportes, v. 18, n. 3, p. 72-79, set. 2010.

LONČAR-VICKOVIĆ, S. et al. Student

Workshops in Engineering Education: case studies at the faculty of civil engineering in Osijek, Croatia. International Journal of Engineering Education, v. 28, n. 4, p. 845-851, 2012.

LÓPEZ-QUEROL, S. et al. Improving Civil Engineering Education: transportation geotechnics taught through project-based learning methodologies. Journal of Professional Issues in Engineering Education and Practice, v. 141, n. 1, 2015.

\section{MAASTRICH UNIVERSITY. Problem Based}

Learning. Disponível em:

$<$ https://www.maastrichtuniversity.nl/education/w hy-um/problem-based-learning>. Acesso em: 15 ago. 2017.

MARQUES FILHO, J. Currículo de Engenharia Civil e Mercado. Concreto \& Construções, v. 87, p. 43-49, 2017.

ODEH, S.; MCKENNA, S.; ABU-MULAWEH, H. A Unified First-Year Engineering DesignBased Learning Course. International Journal of Mechanical Engineering Education, v. 45, p. 47 58, 2017.

PEREIRA, E. M. A. Implicações da PósModernidade Para a Universidade. Revista Avaliação, v. 7, n. 1, mar. 2002.

PICHI JUNIOR., W.; GATTI, D. C.; SILVA, M. L. P Interdisciplinaridade Como Consequência de Trabalhos Conjuntos Entre Nível Técnico e Superior. Revista de Ensino de Engenharia, v. 34, n. 1, p. 51-60, 2015.

PRINCE, M. J.; FELDER, R. M. Inductive Teaching and Learning Methods: definitions, comparisons, and research bases. Journal of Engineering Education, v. 95, n. 2, p. 123-138, Apr. 2006.

PURCELL, K. et al. How Teens do Research in Digital World: part v: teachers' concerns about broader impacts of digital technologies on their students. PEW RESEARCH CENTER. 2012. Disponível em:

$<$ http://www.pewintwenet.org/2012/11/01/part-vteachers-concerns...>. Acesso em: 15 ago. 2018.

RAHMAT, R. A. A. O. K.; AZIZ, N. A. Stimulating Learning Ownership to Engineering Students Via Learning Contract. Asian Social Science, v. 8, n. 3, p. 57-64, 2012. 
REIS, A. C. B.; BARBALHO, S. C. M.; ZANETTE, A. C. D. A Bibliometric and Classification Study of Project-Based Learning in Engineering Education. Production, v. 27, n. 20162258, 2017.

RIBEIRO, L. R. C.; MIZUKAMI, M. G. N. Student Assessment of a Problem-Based Learning Experiment in Civil Engineering Education. Journal of Professional Issues in Engineering Education and Practice, v. 131, n. 1, p. 13-18, Jan. 2005.

RUSCHEL, R. C. et al. O Papel das Ferramentas BIM de Integração e Compartilhamento no Processo de Projeto da Indústria da Construção Civil. Revista Eletrônica de Engenharia Civil, v. 7, n. 3, p. 36-54, 2013.

SHEKHAR, P.; BORREGO, M. Implementing Project-Based Learning in a Civil Engineering Course: a practitioner's perspective. International Journal of Engineering Education, v. 33, n. 4, p. 1138-1148, 2017.

SILVA, A. N. R. da; KURI, N. P.; CASALE, A. PBL and B-Learning For Civil Engineering Students in a Transportation Course. Journal of Professional Issues in Engineering Education and Practice, v. 138, n. 4, p. 305-313, 2012.

SILVA, C. A. P. da; FONTENELE, H. B.; SILVA, A. N. R. da. Transportation Engineering Education For Undergraduate Students: competencies, skills, teaching-learning, and evaluation. Journal of Professional Issues in Engineering Education and Practice, v. 141, n. 3, 2015.
SILVA, W. A. da et al. Avaliação das Estratégias de Ensino no Curso de Engenharia Civil da Universidade Federal de Goiás - Regional Catalão. Revista de Ensino de Engenharia, v. 35, n. 1, p. 11-22, 2016.

SOETANTO, R. et al. Virtual Collaborative Learning For Building Design. Proceedings of Institution of Civil Engineers: Management, Procurement and Law, v. 167, n. 1, p. 25-34, 2014.

SOLÍS, M.; ROMERO, A.; GALVÍN, P. Teaching Structural Analysis Through Design, Building, and Testing. Journal of Professional Issues in Engineering Education and Practice, v. 138, n. 3, p. 246-253, 2012.

STEINEMANN, A. Implementing Sustainable Development Through Problem-Based Learning: pedagogy and practice. Journal of Professional Issues in Engineering Education and Practice, v. 129, n. 4, p. 216-224, 2003.

VANDEBONA, U; ATTARD, M. M. A ProblemBased Learning Approach in a Civil Engineering Curriculum. World Transactions on Engineering and Technology Education. v. 1, n. 1, 2002.

VIDIC, A. D. Using a Problem-Based Learning Approach to Incorporate Safety Engineering Into Fundamental Subjects. Journal of Professional Issues in Engineering Education and Practice, v. 142, n. 2, 2016.

\section{Agradecimentos}

As autoras agradecem à Amanco pela doação de tubos e de conexões para montagens dos "kits" de esgoto sanitário.

\section{Letícia Santos Machado de Araújo}

Construção Civil | Instituto Federal de Educação, Ciência e Tecnologia de São Paulo | Rua Pedro Vicente, 625, Canindé | São Paulo - SP Brasil | CEP 01109-010 | Tel.: (11) 2763-7552 | E-mail: leticia@ifsp.edu.br

\section{Marina Sangoi de Oliveira Ilha}

Departamento de Arquitetura e Construção | Universidade Estadual de Campinas | Rua Saturnino de Brito, 224, Cidade Universitária Zeferino Vaz | Campinas - SP - Brasil | CEP 13083-889 | Tel.: (19) 3521-2306 | E-mail: milha@fec.unicamp.br

Revista Ambiente Construído

Associação Nacional de Tecnologia do Ambiente Construído

Av. Osvaldo Aranha, 99 - 3o andar, Centro

Porto Alegre - RS - Brasil CEP $90035-190$

Telefone: +55 (51) 3308-4084 Fax: +55 (51) 3308-4054

www. seer. ufrgs. br/ ambienteconstruido

E-mail: ambienteconstruido@ufrgs.br 